\title{
One-pot synthesis of $(S)$-2-(6-methoxynaphtalen-2-yl)propanoic acid, $(S)$-Naproxen using Preyssler and Keggin-type heteropolyacids as green and reusable catalysts
}

\author{
Ali Gharib ${ }^{1,2, *}$, Mohsen Daneshtalab ${ }^{3}$, J. (Hans) W. Scheeren ${ }^{4}$, Fatemeh. F. Bamoharram ${ }^{1}$, \\ Mina Roshani ${ }^{1}$, Manouchehr Jahangir ${ }^{1}$
}

${ }^{1}$ Department of Chemistry, School of Science, Islamic Azad University, Mashhad, IRAN

${ }^{2}$ Agricultural Researches and Services Center, Mashhad, IRAN

${ }^{3}$ School of Pharmacy, Memorial University of Newfoundland, St. John's, Newfoundland, Canada A1C 3V6

${ }^{4}$ Cluster for Molecular Chemistry, Department of Organic Chemistry, Radboud University Nijmegen, The Netherlands

*Corresponding author: aligharib5@yahoo.com

\begin{abstract}
A simple, clean and environmentally benign route to the enantioselective synthesis of $(S)-2-(6-$ methoxynaphtalen-2-yl)propanoic acid, $(S)$-Naproxen 3 is described by using Preyssler heteropolyacid, $\mathrm{H}_{14}\left[\mathrm{NaP}_{5} \mathrm{~W}_{30} \mathrm{O}_{110}\right]$, as a green and reusable catalyst in water and in the presence of 1-(6-methoxynaphthalen2-yl)propan-1-one 1, D-mannitol 2 . The products were obtained in very good yields.
\end{abstract}

Keywords: Preyssler, catalyst, heteropolyacid, D-mannitol, $(S)$-Naproxen.

\section{INTRODUCTION}

Heteropolyacids catalyze a wide variety of reactions in homogeneous or heterogeneous (liquid-solid, gas-solid or liquid-liquid biphasic) systems, offering strong options for more efficient and cleaner processing compared to conventional mineral acids ${ }^{1-5}$. Being stronger acids, heteropolyacids will have significantly higher catalytic activity than the conventional catalysts such as mineral acids, mixed-oxides, zeolites, etc. In particular, in organic media, the molar catalytic activity of heteropolyacid is often $100-1000$ times higher than that of $\mathrm{H}_{2} \mathrm{SO}_{4}{ }^{2-4}$. Solid heteropolyacids possess purely Brønsted acidity and are stronger than such conventional solid acids as $\mathrm{SiO}_{2}-\mathrm{Al}_{2} \mathrm{O}_{3}, \mathrm{H}_{3} \mathrm{PO}_{4} / \mathrm{SiO}_{2}$, and $\mathrm{HX}$ and $\mathrm{HY}$ zeolites ${ }^{1-5}$.

Naproxen has different names in pharmaceutical trade such as, Naprosyn ${ }^{\circledR}$, Synflex $^{\circledR}$, and first NSAID marketed in an enantiomerically pure form. $(S)$-enantiomer is 28 times more active than the $(R)$-enantiomer. $\alpha$-Arylpropionic acids are an important classification of non-steroidal anti-inflammatory agents ${ }^{6}$. The therapeutic efficacy of this class of drugs is well demonstrated by the introduction and extensive use of more than a dozen compounds exemplified by ibuprofen, naproxen, ketoprofen and flurbiprofen, etc. However, in recent years, the use of enantiomerical pure drugs in chemotherapy is becoming almost mandatory for enhancing the specificity of drug action and reducing toxicity. This awareness has led to great efforts for obtaining the optical pure isomer of this class of drugs. So far numerous asymmetric reactions have been reported ${ }^{5}$. Currently the practical method for optical pure compounds appears based on an entirely different strategy stereospecific 1, 2-aryl rearrangements ${ }^{7}$. Naproxen is industrially produced by Syntex Process, which involves a multi-step organic synthesis (Sheldon 1996) leading to a significant waste products formation and poor yields. Catalytic oxidation of aldehyde is one of the most promising reactions to achieve the corresponding carboxylic acid in high yields. Oxidation of 2-(6 methoxynaphthyl) propanaldehydes is thus a convenient method for Naproxen synthesis (Barner et al. 1997) on which no significant report has been published. In a report by Barner et al. 88.5\% Naproxen yield was achieved using 2,6-lutidine in peracetic acid solution at $2^{\circ} \mathrm{C}^{8}$. During the past decades enormous progress was made in asymmetric catalytic synthesis, a well-known example is BINAP, ${ }^{9}$ the chiral hydrogenation synthesis of $(S)$-Naproxen catalyzed by BINAP-Ru dicarboxylate complexes provides excellent enantioselectivity (up to $99 \%$ ee) and good chemical yield (92\%), however the pressure is relatively high $(135-150$ $\mathrm{atm})$ and the (S)-BINAP-Ru(III) complex is very expensive. This problem may present a practical limitation. In recent years new methodologies have also been studied such as asymmetric methylation of 2-arylacetic acids, asymmetric hydroformylation/ hydrocarboxylation of the appropriate styrene derivatives, asymmetric alkylation of appropriate aromatic compounds. Unfortunately, the optical yields in these latter cases $^{\mathbf{1 0}}$ are far from excellent. (6-Methoxyl-2-naphthyl)-2-acrylic acids constitute an important class of the substrates for this reaction because the resulting $\alpha$-aryl-2-propanic acids are a variety of commercially important non-steroidal anti-inflammatory agents ${ }^{11}$. Because of the current commercial importance of these well-known anti-inflammatory drugs, naproxen and its derivatives, we chosen (6-methoxyl-2-naphthyl)-2acrylic acid as precursor for our initial studies.

\section{EXPERIMENTAL}

\section{Chemical}

All chemicals were obtained from Merck and used as received.

\section{Instruments}

The ${ }^{1} \mathrm{H}-\mathrm{NMR}$ spectra were recorded on an FT-NMR Bruker $100 \mathrm{MHz}$ Aspect 3000 spectrometer and ${ }^{1} \mathrm{H}$ NMR and ${ }^{13} \mathrm{C}$ NMR spectra were recorded at $298^{\circ} \mathrm{K}$. The IR spectra were obtained with a Bucker 500 scientific spectrometer ( $\mathrm{KBr}$ pellets). The GC-Mass analysis was performed on a GC-Mass model: 5973 network mass selective detector, GC 6890 Agilent. The mass spectra were scanned on a Varian Mat. $\mathrm{CH}-7$ at $70 \mathrm{ev}$. UV-Vis 
spectra were measured on a Shimadzu spectrophotometer. The melting points were recorded on an Electrothermal type 9100 melting point apparatus and were uncorrected. Chemical shifts were reported in ppm $(\delta$-scale) relative to the internal standard TMS (0.00 ppm); the solvent was used as a reference. TLC was carried out with E. Merck Silica gel GOF-254 (0.25 mm thickness) pre-coated tic plates. The Column Chromatography was carried out with the silica gel (Kieselgel 60, 70-230 mesh, E. Merck).

\section{Catalyst preparation}

All the chemical compounds and Keggin type heteropolyacids were acquired from commercial sources. Preyssler, $\mathrm{H}_{14}\left[\mathrm{NaP}_{5} \mathrm{~W}_{30} \mathrm{O}_{110}\right]$ or $\left(\mathrm{H}_{14}-\mathrm{P}_{5}\right)$, $\mathrm{H}_{14}\left[\mathrm{NaP}_{5} \mathrm{~W}_{29} \mathrm{MoO}_{110}\right]$ or $\left(\mathrm{H}_{14}-\mathrm{P}_{5} \mathrm{Mo}\right)$ and supported Preyssler on silica, $\mathrm{H}_{14} \mathrm{P}_{5} / \mathrm{SiO}_{2}$ were prepared in accordance with the earlier reports ${ }^{12,13}$ and $\mathrm{H}_{4}\left[\mathrm{PMo}_{11} \mathrm{VO}_{40}\right]$ and $\mathrm{H}_{5}\left[\mathrm{PMo}_{10} \mathrm{~V}_{2} \mathrm{O}_{40}\right]$, Wells-Dawson, $\left(\mathrm{H}_{6}\left[\mathrm{P}_{2} \mathrm{~W}_{18} \mathrm{O}_{62}\right]\right)$, $\mathrm{H}_{7}\left[\mathrm{PMo}_{8} \mathrm{~V}_{4} \mathrm{O}_{40}\right], \mathrm{PW}_{11}, \mathrm{PW}_{11} \mathrm{NiO}_{40}, \mathrm{PW}_{11} \mathrm{ZnO}_{40}$, $\mathrm{PW}_{11} \mathrm{CoO}_{40}$ were prepared in accordance with the literature $5,13-17,2$.

\section{Synthesis of the $(S)$-Naproxen $(3)$}

A mixture of 1-(6-methoxynaphthqlen-2-yl) propan-1one 1 (15 mmol), D-mannitol 2 (3.45 g, $15 \mathrm{mmol})$ and heteropolyacids catalyst $(0.06 \mathrm{mmol})$ dissolved in DMF $(50 \mathrm{~mL})$, was stirred and refluxed for $3.5 \mathrm{~h}$. The resulting solution was concentrated under reduced pressure, the residue was extracted by ethanol $(3 \times 30 \mathrm{~mL})$ and the solvent was recovered, the residue was isolated by the chromatograph on the silica column and obtained two types of ester (esters $\mathbf{1}$ and 2).

The residue was chromatographed on the silica column $\left(\mathrm{CH}_{2} \mathrm{Cl}_{2}: \mathrm{CHCl}_{3}=70: 30\right)$ and two components were obtained, as follows:

Ester $1\left(\mathrm{C}_{20} \mathrm{H}_{26} \mathrm{O}_{8}\right)$ : M.p. $83-84^{\circ} \mathrm{C},[\alpha]^{20}{ }_{\mathrm{D}}+98$ (c 1.8 . $\mathrm{CHCl}_{3}$ ), yield $96.5 \%$, ee $98 \%$.

Elemental Analysis: Calcd.: C 60.9\%, H 6.6\%; Found C 60.7\%, H 6.7\%; MS (m/z): $394\left(\mathrm{M}^{+}\right) .{ }^{1} \mathrm{H}-\mathrm{NMR}(100$ MHz, DMF-d $\left.\mathrm{d}_{7}\right): 7.5\left(\mathrm{~m}, 6 \mathrm{H}\right.$, naphthyl), $4.2\left(\mathrm{~s}, 3 \mathrm{H}, \mathrm{OCH}_{3}\right)$, $1.3\left(\mathrm{~d}, 3 \mathrm{H}, \mathrm{J}=7.4 \mathrm{~Hz}, \mathrm{CH}_{3}\right), 3.5(\mathrm{q}, 1 \mathrm{H}, \mathrm{J}=7.5 \mathrm{~Hz}, \mathrm{CH})$, $3.8-4.9(\mathrm{~m}, 8 \mathrm{H}, \mathrm{CH}), 5.1(\mathrm{~s}, 5 \mathrm{H},-\mathrm{OH})$;

${ }^{13} \mathrm{C} \mathrm{NMR}\left(100 \mathrm{MHz}, \mathrm{CDCl}_{3}\right): 24.35,49.86,5310,55.40$, $65.50,73.99,95.24,103.61,117.41,123.94,127.23$, 128.14, 140.01, 144.46, 161.37, 176.88.
IR $\left(\mathrm{KBr}, v_{\max } / \mathrm{cm}^{-1}\right): 3450,2900,1725,1603,1540$, 1445, 1320, 1225, 1110, 1030, 985, 780, 680. HRMS Calcd for $\mathrm{C}_{20} \mathrm{H}_{26} \mathrm{O}_{8}$ : 394.028. Found: 394.025.

Ester $2\left(\mathrm{C}_{34} \mathrm{H}_{38} \mathrm{O}_{10}\right)$ : M.p. $83-84^{\circ} \mathrm{C},[\alpha]^{20}{ }_{\mathrm{D}}+156$ (c 1.8. $\mathrm{CHCl}_{3}$ ), yield $93.5 \%$, ee $95 \%$.

Elemental Analysis: Calcd. C 67.3\%, H 6.3\%; Found C 67.2\%, H 6.1\%; MS (m/z): $606\left(\mathrm{M}^{+}\right) .{ }^{1} \mathrm{H}-\mathrm{NMR}(100$ $\left.\mathrm{MHz}, \mathrm{DMF}-\mathrm{d}_{7}\right): 7.5(\mathrm{~m}$, naphthyl, $12 \mathrm{H}), 4.1\left(\mathrm{~s}, 6 \mathrm{H}, \mathrm{OCH}_{3}\right)$, $1.4\left(\mathrm{~d}, 6 \mathrm{H}, \mathrm{J}=7.6 \mathrm{~Hz}, \mathrm{CH}_{3}\right), 3.5(\mathrm{q}, 2 \mathrm{H}, \mathrm{J}=7.4 \mathrm{~Hz}, \mathrm{CH})$, 3.7-4.9(m, 8H, CH), 5.1(s, 4H, -OH);

${ }^{13} \mathrm{C}$ NMR (100 $\left.\mathrm{MHz}, \mathrm{CDCl}_{3}\right):$ 24.35, 53.22, 55.40, $63.25,66.53,68.79,69.25,71.38,103.61,117.41,124.04$, $127.28,128.25,140.35,144.46,161.37,178.42$.

IR $\left(\mathrm{KBr}, v_{\max } / \mathrm{cm}^{-1}\right): 3450,2900,1725,1605,1540$, 1445, 1320, 1225, 1110, 1030, 985, 780, 685.

HRMS Calcd for $\mathrm{C}_{34} \mathrm{H}_{38} \mathrm{O}_{10}: 606.054$. Found: 606.051. The residue was dissolved in a mixture of methanol (50 $\mathrm{mL})$ and heteropolyacids (HPAs) catalyst $(0.06 \mathrm{mmol})$ and was refluxed for $2.5 \mathrm{~h}$. After the reaction completion, the reaction mixture was cooled and $\mathrm{NaOH}(2 \mathrm{~mol} / \mathrm{L})$ was added to the reaction mixture to neutralize the solution. The mixture was extracted by chloroform $(3 \times 30 \mathrm{~mL})$ and washed with water, then chromatographed on the silica column $\left(\mathrm{CH}_{2} \mathrm{Cl}_{2}: \mathrm{C}_{2} \mathrm{H}_{5} \mathrm{OH}=70: 30\right)$, a white product $(S)$ 2-(6-methoxynaphtalen-2-yl) propanoic acid, $(S)$-Naproxen 3 was obtained, and then analyzed. The products were characterized by the comparison of their spectroscopic (IR, ${ }^{1} \mathrm{H}$ NMR, Mass, ${ }^{13} \mathrm{C}$ NMR) data with those of the authentic samples. The yields were determined by GC. (3.26 g, $94.5 \%$ ). M.p. $152-155^{\circ} \mathrm{C},[\alpha]^{20}{ }_{\mathrm{D}}+63.4$ (c 1.8 . $\mathrm{CHCl}_{3}$ ), ee $99 \%$. [M.p. $154-156^{\circ} \mathrm{C},[\alpha]^{20}{ }_{\mathrm{D}}+63.5$ (c 1.8 . $\left.\left.\mathrm{CHCl}_{3}\right)\right]^{17}$.

Elemental Analysis: Calcd. C 72.40\%, H 6.08\%; Found C $71.97 \%$, H $6.18 \%$;

MS (m/z): $230\left(\mathrm{M}^{+}, 53\right), 185$ (100), 170 (1), 154 (7), 141 (11), 115 (9), 77 (2), 63 (2) ;

${ }^{1} \mathrm{H}-\mathrm{NMR}$ (100 MHz, DMF-d $\left.{ }_{7}\right): 7.5(\mathrm{~m}, 6 \mathrm{H}$, naphthyl), $4.2\left(\mathrm{~s}, 3 \mathrm{H}, \mathrm{OCH}_{3}\right), 1.3(\mathrm{~d}, 3 \mathrm{H}, \mathrm{J}=7.4 \mathrm{~Hz}, \mathrm{CH} 3), 3.5(\mathrm{q}$, $1 \mathrm{H}, \mathrm{J}=7.5 \mathrm{~Hz}, \mathrm{CH}), 11.8(\mathrm{~s}, 1 \mathrm{H}, \mathrm{OH}) .{ }^{13} \mathrm{C}$ NMR $(100$ $\left.\mathrm{MHz}, \mathrm{CDCl}_{3}\right): 22.46,51.52,55.40,104.52,118.32,127.28$, 127.46, 140.19, 144.22, 161.37, 177.08.

IR $\left(\mathrm{KBr}, v_{\max } / \mathrm{cm}^{-1}\right): 3300,2850,1730,1600,1530$, 1435, 1330, 1215, 1120, 1010, 980, 785, 675. HRMS Calcd for $\mathrm{C}_{14} \mathrm{H}_{14} \mathrm{O}_{3}$ : 230.0943. Found: 230.0940 .

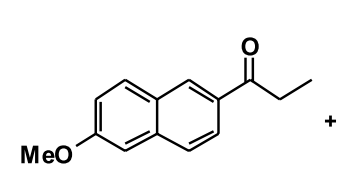

1

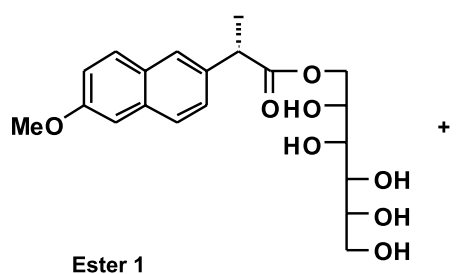

Ester 1

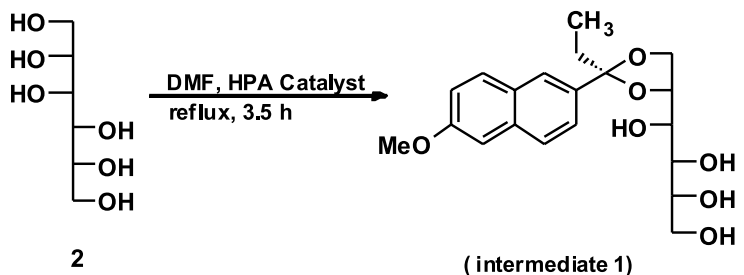

( intermediate 1)

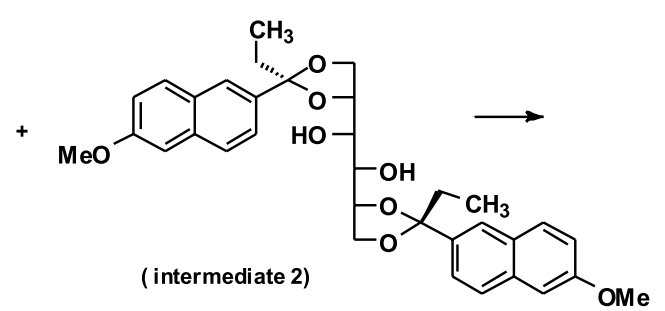

(intermediate 2)

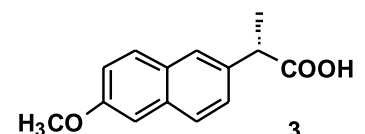

Scheme 1. Synthesis of $(S)$-Naproxen 3 in the presence of heteropolyacids (HPAs) as the catalyst and reflux conditions 
UV-VIS (MeOH (log $\varepsilon)): 262$ (3.07), 271 (3.71), 316 (3.16), 331 (3.26).

\section{RESULTS AND DISCUSSION}

We wish to report a new method for the catalytic synthesis of $(S)$-Naproxen $\mathbf{3}$ using heteropolyacids as the catalyst in the presence of 1-(6-methoxynaphthqlen-2-yl) propan-1-one 1, with D-mannitol 2 as auxiliary (Scheme 1).

In continuation with our works by using heteropolyacids ${ }^{\mathbf{1 6}}$ which are low in toxicity, highly stable towards humidity, recyclable, air stable, and very important in green chemistry. We studied this reaction with heteropolyacid catalysts including W, Mo, such as $\mathrm{H}_{3}$ $\left[\mathrm{PMo}_{12} \mathrm{O}_{40}\right]$ and Preyssler, $\mathrm{H}_{14}\left[\mathrm{NaP}_{5} \mathrm{~W}_{30} \mathrm{O}_{110}\right]$. When the mixture of 1-(6-methoxynaphthqlen-2-yl)propan-1-one 1 and D-mannitol 2 in DMF was refluxed in the presence of the catalytic amounts of the mentioned heteropolyacids, (S)-2-(6-methoxynaphtalen-2-yl)propanoic acid, ((S)Naproxen) 3 were obtained with the $90.5 \%$ yield and the 99\% ee (Scheme 1).

The synthesis of the optically active acetals and stereospecific rearrangements is shown in (Scheme 1,2). In this reaction, three types of the ketals can be produced using D-mannitol 2 and 1-(6-methoxynaphthqlen-2yl)propan-1-one $\mathbf{1}$ in the presence of heteropolyacids (HPAs) catalysts, but only two kinds of optical active acetals $\mathbf{1}$ and $\mathbf{2}$ were obtained. This result may be due to the "space effect "in this reaction.

However, when $\mathrm{CH}_{3} \mathrm{OH}$ and heteropolyacid were allowed to be stirred and refluxed with $\alpha$-naphthyl-glycidyl ether for $2.5 \mathrm{hr}$, followed by the addition of $\mathrm{NaOH}(10 \%)$ to the same reaction vessel, it gave $(S)$-Naproxen 3 in good chemical yield and optical purity. The enantiomeric ex-

Table 1. The yields of heteropolyacid catalyzed enantioselective synthesis of $(S)$-Naproxen $\mathbf{3}$ with a variety mole ration of the substrates $\mathbf{1}$ and $\mathbf{2}$

\begin{tabular}{|l|l|l|l|}
\hline Entry & ${ }^{a}$ Mole ratio & ${ }^{b}$ Yield $\%$ & ${ }^{c}$ ee $\%$ \\
\hline 1 & $1: 0.5$ & 94.5 & 99 \\
\hline 2 & $1: 1$ & 90 & 42 \\
\hline 3 & $1: 0.05$ & 87 & 25 \\
\hline 4 & $1: 0.07$ & 89 & 21 \\
\hline 5 & $1: 0$ & 80 & 0 \\
\hline
\end{tabular}

a) Mole ratio corresponding to 1-(6-methoxynaphthalen-2-yl) propan-1-one: D-mannitol. b) Isolated yield. c) Calculated by correlation of optical rotation $[\alpha]\left(\mathrm{C}=1.8, \mathrm{CHCl}_{3}\right)$ with literature values $^{26},[\alpha]_{D}^{20}+63.4\left(\mathrm{C}=1.8, \mathrm{CHCl}_{3}\right)$.

cess was calculated by the correlation of optical rotation $[\alpha]$ with literature values of $[\alpha]^{20}{ }_{D}+63.4(\mathrm{C}=1.8$, $\left.\mathrm{CHCl}_{3}\right)^{17}$. Mole ratios of 1-(6-methoxynaphthqlen-2-yl) propan-1-one 1: D-mannitol 2 were affected in chemical and optical yields. So, the best mole ratio is $1: 0.5$ with 94.5\% isolated yield of crude product which showed $99 \%$ ee of (S)-enantiomer (Table 1).

In comparison with the literature report ${ }^{17}$, we have shown that (S)-Naproxen $\mathbf{3}$ with high purity (99\% ee) and the chemical yield ( $94.5 \%$ overall yield) can be obtained in only two steps without any purification or resolution of the intermediate. We suggested a preliminarily chiral complex, which kinetically favoured for $(S)$ enantiomer responsible for this optical purity. Finally, we can con- clude that enantioselective by using methanol/ heteropolyacid in hydrolysis of esters is an efficient alternative short route, with simple work up and high enantiomeric excess for the synthesis of $(S)$-Naproxen 3. Generally, the residue (esters $\mathbf{1}$ and $\mathbf{2}$ ) is dissolved directly into the mixture of methanol and heteropolyacid and refluxed for $2.5 \mathrm{~h}$. After cooled to the room temperature, the mixture is neutralized by $\mathrm{NaOH}$ solution to $\mathrm{pH}=6-7$, extracted by $\mathrm{CHCl}_{3}$ three times and washed with water, concentrated, finally chromatographed on the silica column $\left(\mathrm{CH}_{2} \mathrm{Cl}_{2}: \mathrm{C}_{2} \mathrm{H}_{5} \mathrm{OH}=70: 30\right)$.

We carried out the hydrolysis reaction of esters 1 and $\mathbf{2}$ in the presence of heteropolyacids types as the catalyst under the same conditions, the results were very useful for the synthesis of $(S)$-Naproxen 3, because Preyssler type catalyst gave a higher yield than Keggin and Wells-Dawson types (Table 2). Generally, the heteropolyacids-catalyzed reactions may be represented by the conventional mechanisms of Brønsted acid catalysis. The mechanism may start with the protonation of the substrates and followed by the conversion of the ionic intermediates to the related products ${ }^{3,4}$ and the strong acids readily cleave ethers. However, acetals, ketals are easily cleaved by dilute acids, these compounds are hydrolyzed with greater facility because carbocations are greatly stabilized by resonance.

Misono and co-workers advanced two types of catalysis for the heterogeneous acid catalysis by heteropolyacids as surface type and bulk type ${ }^{19}$. The discussions on the behavior of carbocation intermediates in the superacid media and of neighboring-group participation have already provided examples of carbocation rearrangements. This is a characteristic feature of carbocations. In this reaction, rearrangements occurred by the shift of a hydrogen and a methyl group. The rearrangement created a new carbocation with the positive charge located on the carbon atom from which the migration occurred. 1,2-Shifts (methyl and hydride shift) are the most common types of rearrangement, Scheme 2.

Since chiral centers are most commonly tetrahedral, the conversion of trigonal centers to tetrahedral centers by some type of addition process is the most common way in which new chiral centers are created and they are optically active. The reaction of carbonyl groups with nucleophiles is a classic example. If the substituents on the carbonyl group and the nucleophile are all different, then a new chiral center is produced, as in the reaction of 1-(6-methoxynaphthalen-2-yl)propan-1-one with D-mannitol to produce hemiacetals (the product of the addition of one molecule of alcohol to a ketone is referred to as a hemiacetal) and acetals (dehydration followed by the addition of a second molecule of alcohol gives an acetal) with optical activity. This second phase of the process can be catalyzed only by acids because a necessary step is the elimination of hydroxide (as water) from the tetrahedral intermediate, Scheme 3.

The carbonyl group is trigonal and planar and can be thought of as having two faces. Addition of nucleophile to one face gives one enantiomer while the addition to the opposite face gives the opposite enantiomer. As rewritten below, the attack from the above gives the $\mathrm{R}$ enantiomer while the attack from below gives the $\mathrm{S}$ enantiomer. The faces are stereochemically nonequivalent since different stereoisomers are produced. 

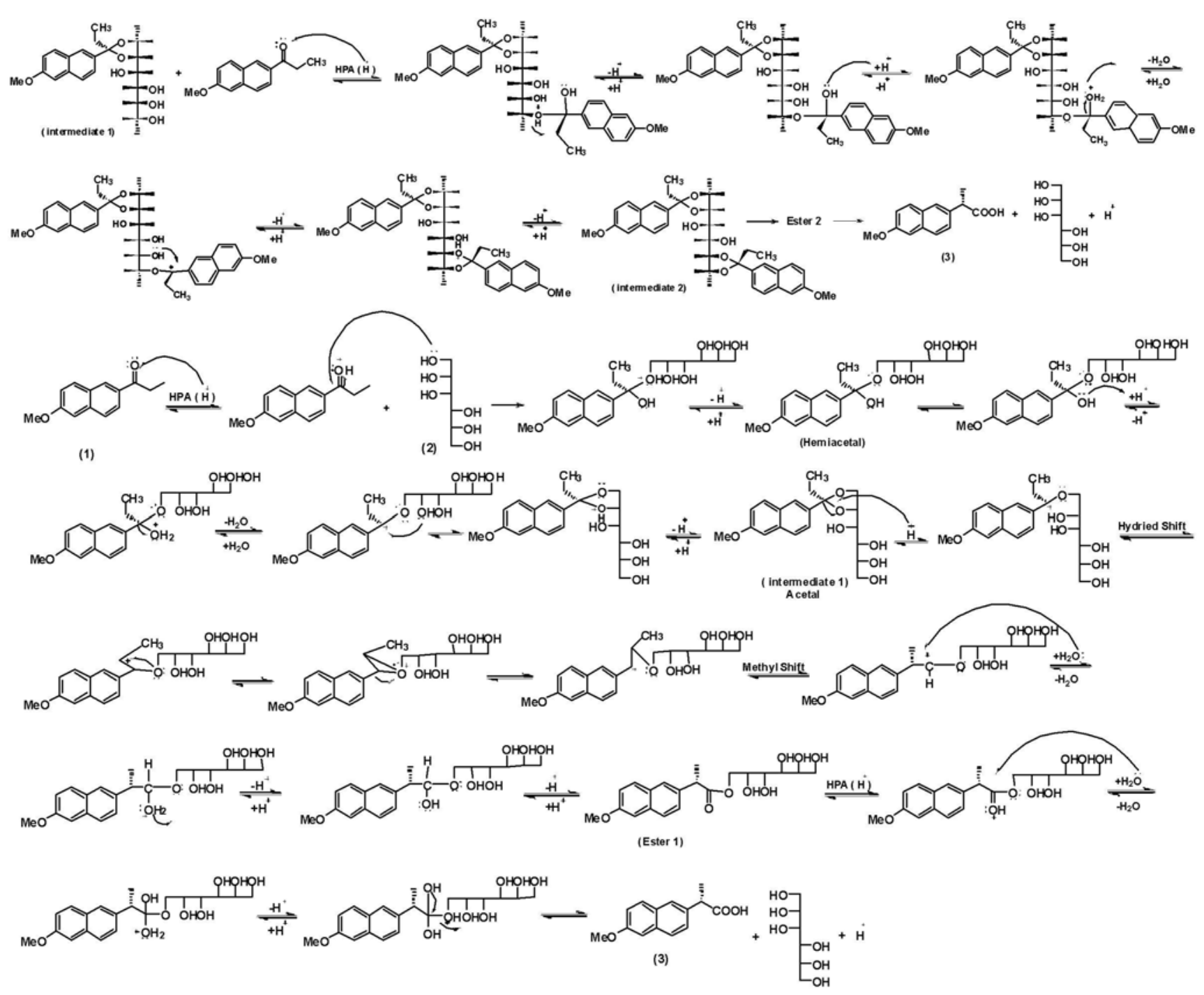

Scheme 2. Mechanism of the synthesis of $(S)$-Naproxen 3

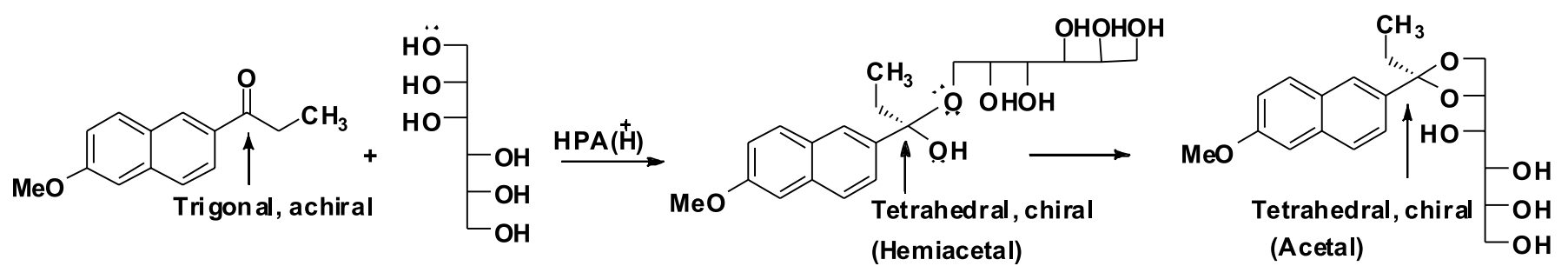

Scheme 3. Formation of enantiomers<smiles>CCC(CC)C(=O)c1ccc2cc(OC)ccc2c1</smiles><smiles>CCC(=O)c1ccc2cc(OC)ccc2c1</smiles>

Figure 1. The reaction of carbonyl groups with Nucleophile from two faces

To differentiate the faces of a carbonyl group, the ReSi nomenclature has been developed. The groups around the carbonyl carbon are given priorities by the same rules used in the Cahn-Ingold-Prelog system for R,S nomenclature. Then, going from the group of highest priority to the group of lowest priority around the face of a carbonyl group, proceeding in the clockwise direction defines the Re face and proceeding in the counter-clockwise direction defines the Si face.
The Re-Si nomenclature enables the faces of a carbonyl group to be differentiated stereochemically; however, the<smiles>CCOC(=O)c1ccc2cc(OC)ccc2c1</smiles><smiles>[R20]c1cc(OC)cc2cc(C(=O)OC)ccc12</smiles>

Figure 2. The faces of a carbonyl group

carbonyl group itself is achiral. Moreover, the Re-Si designation is not indicative of the stereochemistry of the chiral center produced by addition. In the above example nucleophile addition to the $\mathrm{Si}$ face gives the $\mathrm{R}$ enantiomer while nucleophile addition to the Re face gives the $\mathrm{S}$ enantiomer. 
In acid-catalyzed reactions by heteropolyacids, several types of acid sites are present ${ }^{2,4}$. They include: proton sites in bulk heteropolyacids, Lewis acid sites in their salts (metal counteractions), proton sites in acidic salts, proton sites generated by dissociation of coordinated water and reduction of salts, and proton generated by partial hydrolysis of polyanions. In the surface type catalysis, the

Table 2. The yields of $(S)$-Naproxen 3 synthesis using various heteropolyacids (HPAs) under reflux temperature condition

\begin{tabular}{|l|l|l|}
\hline Entry & Catalyst & ${ }^{a}$ Yield $\%$ \\
\hline 1 & $\mathrm{H}_{14}\left[\mathrm{NaP}_{5} \mathrm{~W}_{30} \mathrm{O}_{110}\right]$ & 94.5 \\
\hline 2 & $\mathrm{H}_{14}\left[\mathrm{NaP}_{5} \mathrm{~W}_{29} \mathrm{MoO}_{110}\right]$ & 89.5 \\
\hline 3 & $\mathrm{H}_{3}\left[\mathrm{PMo}_{12} \mathrm{O}_{40}\right]$ & 59 \\
\hline 4 & $\mathrm{H}_{3}\left[\mathrm{PW}_{12} \mathrm{O}_{40}\right]$ & 64.5 \\
\hline 5 & $\mathrm{H}_{4}\left[\mathrm{SiW}_{12} \mathrm{O}_{40}\right]$ & 60 \\
\hline 6 & $\mathrm{H}_{4}\left[\mathrm{SiMo}_{12} \mathrm{O}_{40}\right]$ & 50 \\
\hline 7 & $\mathrm{H}_{4}\left[\mathrm{PMo}_{11} \mathrm{~V}_{1} \mathrm{O}_{40}\right]$ & 67 \\
\hline 8 & $\mathrm{H}_{5}\left[\mathrm{P} \mathrm{Mo}_{10} \mathrm{~V}_{2} \mathrm{O}_{40}\right]$ & 72.5 \\
\hline 9 & $\mathrm{H}_{6}\left[\mathrm{PMo}_{9} \mathrm{~V}_{3} \mathrm{O}_{40}\right]$ & 75 \\
\hline 10 & $\mathrm{H}_{7}\left[\mathrm{PMo}_{8} \mathrm{~V}_{4} \mathrm{O}_{40}\right]$ & 79.5 \\
\hline 11 & $\mathrm{H}_{6}\left[\mathrm{P}_{2} \mathrm{~W}_{18} \mathrm{O}_{62}\right]$ & 78 \\
\hline 12 & $\mathrm{H}_{14}\left[\mathrm{NaP}_{5} \mathrm{~W}_{30} \mathrm{O}_{110}\right] / \mathrm{SiO}_{2}(10 \%)$ & 29 \\
\hline 13 & $\mathrm{H}_{14}\left[\mathrm{NaP}_{5} \mathrm{~W}_{30} \mathrm{O}_{110}\right] / \mathrm{SiO}_{2}(20 \%)$ & 44 \\
\hline 14 & $\mathrm{H}_{14}\left[\mathrm{NaP}_{5} \mathrm{~W}_{30} \mathrm{O}_{110}\right] / \mathrm{SiO}_{2}(30 \%)$ & 62 \\
\hline 15 & $\mathrm{H}_{14}\left[\mathrm{NaP}_{5} \mathrm{~W}_{30} \mathrm{O}_{110}\right] / \mathrm{SiO}_{2}(40 \%)$ & 71.5 \\
\hline 16 & $\mathrm{H}_{14}\left[\mathrm{NaP}_{5} \mathrm{~W}_{30} \mathrm{O}_{110}\right] / \mathrm{SiO}_{2}(50 \%)$ & 80 \\
\hline
\end{tabular}

${ }^{\text {a }}$ Yields refer to isolated products.

a Yields analyzed by GC.

reactions occur on the surface of the bulk or supported heteropoly compounds and the catalytic activity usually depends on the surface acidity of heteropolyacid. The acidic strength of Preyssler type is much higher than that of other types of heteropolyacids. Preyssler structure has 14 acidic protons, and $\mathrm{W}$ atom has acidic properties more than Mo, Si and V (Table 2).

HPA on Silica, $\mathrm{SiO}_{2}$ is relatively inert toward HPAs, at least above a certain loading level, although some chemical interactions take place between of HPA and $\mathrm{SiO}_{2}$, the interaction is involved between hydroxyl groups of silan and acidic protons of heteropolyacids (Fig 3 ). The results show a decrease in the acidity ability that silica supported Preyssler in the following way:

$10 \%<20 \%<30 \%<40 \%<50 \%$. (Table 2, entries 11 $-15)$.

The acid strength of crystalline heteropolyacids decreases in the series $11-15$ :

$\mathrm{H}_{3}\left[\mathrm{PW}_{12} \mathrm{O}_{40}\right]>\mathrm{H}_{4}\left[\mathrm{SiW}_{12} \mathrm{O}_{40}\right]>\mathrm{H}_{3}\left[\mathrm{PMo}_{12} \mathrm{O}_{40}\right]>$ $\mathrm{H}_{4}\left[\mathrm{SiMo}_{12} \mathrm{O}_{40}\right]$.

The results showed that the catalytic activity of $\mathrm{H}_{14}-\mathrm{P}_{5}$ is higher than that of $\mathrm{H}_{14}-\mathrm{P}_{5}$ Mo.

The mixed addenda heteropoly anions are formed by the substitution of one or more tungsten (VI) or molybdenum (VI) in heteropolyanions by another addenda atom like $\mathrm{W}(\mathrm{VI})$ and $\mathrm{V}(\mathrm{V})$.

The relative activity of Keggin heteropolyacids primarily depends on their acid strength. These properties for the most common heteropolyacids are summarised as follows 9,10 .

The acid strength of crystalline HPAs decreases in the series:

Acid strength $\mathrm{PW}>\mathrm{SiW} \geq \mathrm{PMo}>\mathrm{SiMo}$

The addenda atoms can be ordered by decreasing the oxidizing ability in the following way:
$\mathrm{V}(\mathrm{V})>\mathrm{Mo}(\mathrm{VI})>\mathrm{W}(\mathrm{VI})^{\mathbf{2 0}}$. The mixed addenda Preyssler catalyst is formed by the substitution of one tungsten (VI) ion by Mo (VI). We obtained good results in the synthesis of $(S)$-Naproxen $\mathbf{3}$ by using various heteropolyacids catalysts, and the results of the catalysts effective in the synthesis of $(S)$-Naproxen 3 are as follows: $\mathrm{H}_{14}\left[\mathrm{NaP}_{5} \mathrm{~W}_{30} \mathrm{O}_{110}\right]>\mathrm{H}_{14}\left[\mathrm{NaP}_{5} \mathrm{~W}_{29} \mathrm{MoO}_{110}\right]>$ $\mathrm{H}_{14}\left[\mathrm{NaP}_{5} \mathrm{~W}_{30} \mathrm{O}_{110}\right] / \mathrm{SiO}_{2}(50 \%)>\mathrm{H}_{7}\left[\mathrm{PMo}_{8} \mathrm{~V}_{4} \mathrm{O}_{40}\right]>$ $\mathrm{H}_{6}\left[\mathrm{P}_{2} \mathrm{~W}_{18} \mathrm{O}_{62}\right]>\mathrm{H}_{6}\left[\mathrm{PMo}_{9} \mathrm{~V}_{3} \mathrm{O}_{40}\right]>\mathrm{H}_{5}\left[\mathrm{PMo}_{10} \mathrm{~V}_{2} \mathrm{O}_{40}\right]>$ $\mathrm{H}_{14}\left[\mathrm{NaP}_{5} \mathrm{~W}_{30} \mathrm{O}_{110}\right] / \mathrm{SiO}_{2}(40 \%)>\mathrm{H}_{4}\left[\mathrm{PMo}_{11} \mathrm{~V}_{1} \mathrm{O}_{40}\right]>$ $\mathrm{H}_{3}\left[\mathrm{PW}_{12} \mathrm{O}_{40}\right]>\mathrm{H}_{14}\left[\mathrm{NaP}_{5} \mathrm{~W}_{30} \mathrm{O}_{110}\right] / \mathrm{SiO}_{2}(30 \%)>$ $\mathrm{H}_{4}\left[\mathrm{SiW}_{12} \mathrm{O}_{40}\right]>\mathrm{H}_{3}\left[\mathrm{PMo}_{12} \mathrm{O}_{40}\right]>\mathrm{H}_{4}\left[\mathrm{SiMo}_{12} \mathrm{O}_{40}\right]>$ $\mathrm{H}_{14}\left[\mathrm{NaP}_{5} \mathrm{~W}_{30} \mathrm{O}_{110}\right] / \mathrm{SiO}_{2}(20 \%)>\mathrm{H}_{14}\left[\mathrm{NaP}_{5} \mathrm{~W}_{30} \mathrm{O}_{110}\right] /$ $\mathrm{SiO}_{2}(10 \%)$.

\section{Catalyst reusability}

At the end of the reaction, the catalyst could be recovered by a simple filtration. The recycled catalyst could be washed with dichloromethane and used in the second run of the reaction process. The results of the first and subsequent experiments were almost consistent in the yields.

\section{Effect of the catalyst type}

The progress of the reaction in the synthesis of $(S)$ Naproxen 3, was followed by GC. The yields are shown in Table 1. According to the results, the highest yield of $(S)$-Naproxen 3 has been achieved in the presence of $\mathrm{H}_{14}-\mathrm{P}_{5}$ as catalyst. Thus, we selected $\mathrm{H}_{14}-\mathrm{P}_{5}$ for supporting silica gel $\left(\mathrm{H}_{14}-\mathrm{P}_{5} / \mathrm{SiO}_{2}\right)$. The results show that Preyssler's anion proves to be an efficient catalyst in these reactions with better activity than what Keggins and Dawson studies show about heteropolyacids. The acid strength of this solid acid catalyst is greater than that of other heteropolyacids. It seems clear that the acid strength of the protons on $\mathrm{H}_{14}-\mathrm{P}_{5}$ is sufficient to catalyze the hydrolysis of esters reaction and potentially all protons are active sites.

By replacing one of tungsten atoms of $\mathrm{H}_{14}-\mathrm{P}_{5}$ with molybdenum, the yield is decreased.

The reason for this effect is not clear for us at this time; however, it seems that by replacing tungsten with molybdenum in Preyssler catalyst symmetry is decreased. In this study, the distortion of $\mathrm{H}_{14}-\mathrm{P}_{5} \mathrm{Mo}$ and decrease in acidity is tentatively suggested. The results of the comparison between supported and nonsupported Preyssler catalyst $\left(\mathrm{H}_{14}-\mathrm{P}_{5}\right.$ and $\left.\mathrm{H}_{14}-\mathrm{P}_{5} / \mathrm{SiO}_{2}\right)$ have shown that, in all cases, the supported heteropolyacid is less active than the nonsupported one. One plausible interpretation of this observation is that in $\mathrm{H}_{14}-\mathrm{P}_{5} / \mathrm{SiO}_{2}$, there are polyanion support interactions of an acid-base nature. Some protons of the polyacid and some basic sites of the support (for example hydroxyl groups) can interact.

This would lead to a diminished availability due to this extra ionic interaction ${ }^{4}$. By using different forms of Preyssler catalyst, the observed selectivity was always $100 \%$.

Isolation and separation of the intermediates $\mathbf{1}$ and $\mathbf{2}$ is impossible, because the intermediates $\mathbf{1}$ and $\mathbf{2}$ were converted into esters $\mathbf{1}$ and $\mathbf{2}$ in a short time. The yields for esters 1 and 2 were in order to 96.5 and $93.5 \%$. We have shown that esters $\mathbf{1}$ and $\mathbf{2}$ with high purity in order to (98\% and $95 \%$ ee) can be obtained by the chromatograph system. 

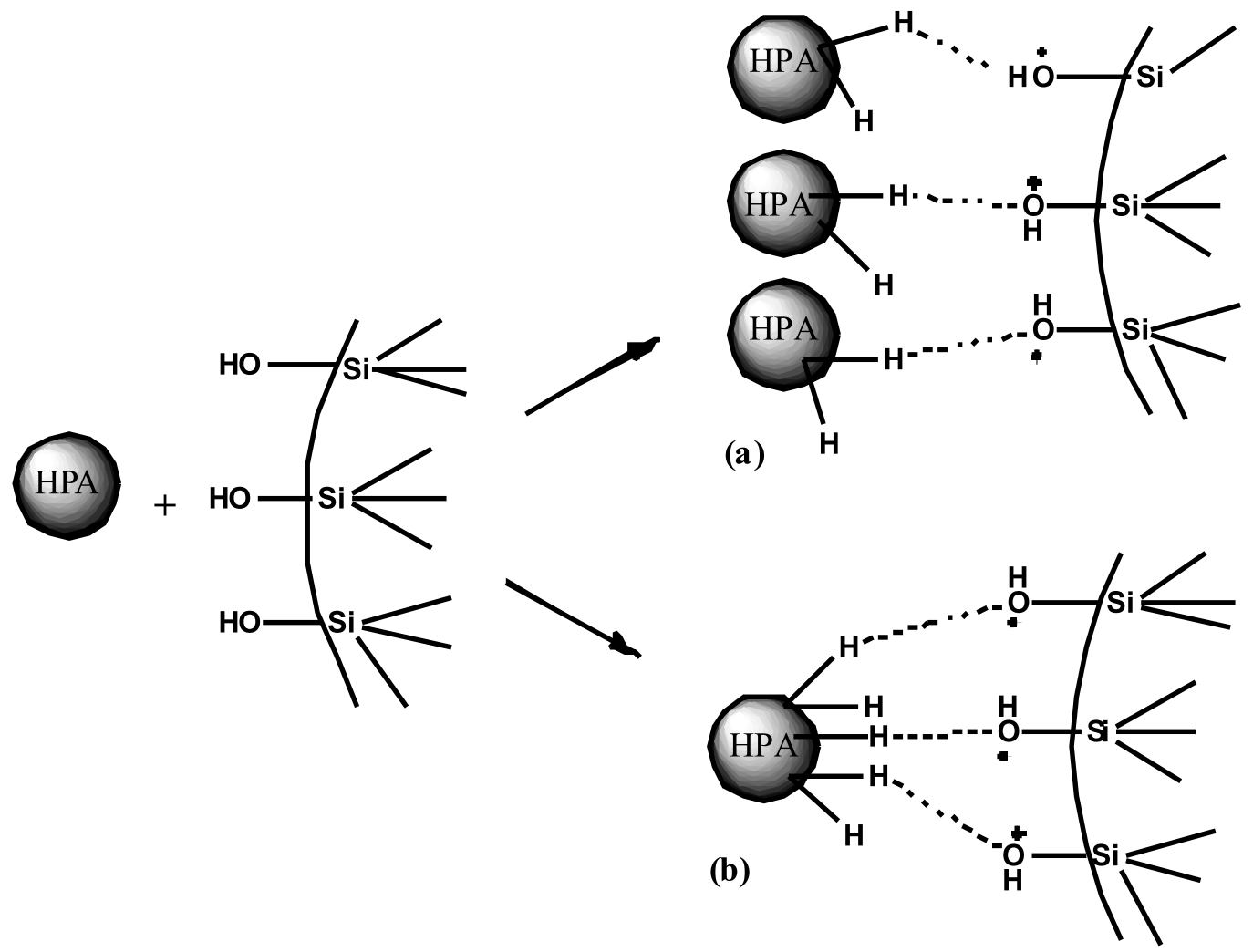

In teraction of $\mathrm{OH}$ gro ups $\mathrm{SiO}_{2}$ with heteropolyacids acidic Protons

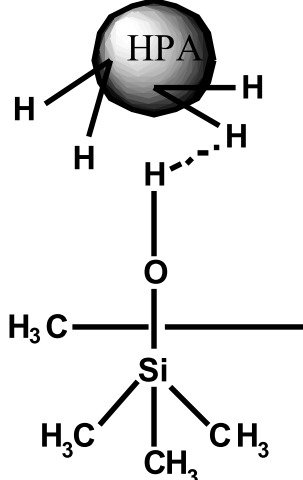

a)

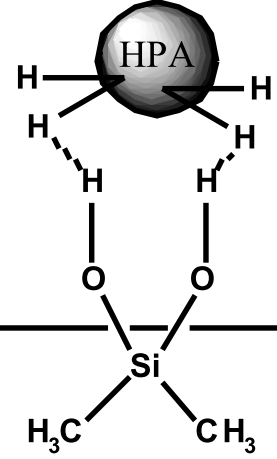

b)

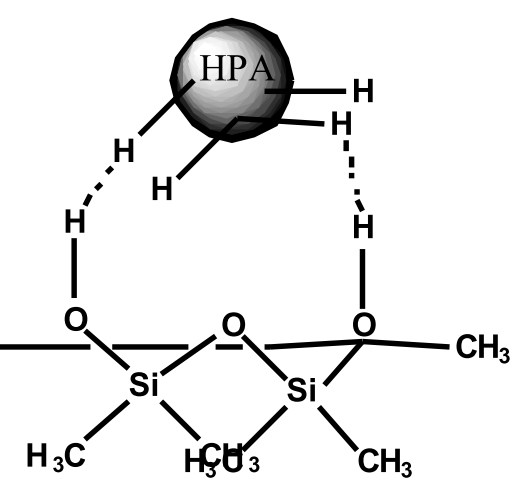

c)

Su rf ace active sites at the silica surf ace; a) isolated silan d group, b) geminal silanol group s, and c) siloxane bridge and interaction of $\mathrm{OH}$ groups $\mathrm{SiO}_{2}$ with heteropol yacids aci dic Proton

Figure 3. A model form of Keggin anion interaction acidic protons of HPAs with hydroxyl silanol groups

\section{CONCLUSION}

In conclusion, we have demonstrated an alternative and simple procedure for the synthesis of $(S)$-Naproxen 3 by using Preyssler catalyst, $\mathrm{H}_{14}\left[\mathrm{NaP}_{5} \mathrm{~W}_{30} \mathrm{O}_{110}\right]$ as an ecofriendly, environment friendly, reusable, inexpensive, non corrosive and efficient catalyst.

High yields, simplicity of operation and an easy workup procedure are some advantages of this protocol.

\section{Acknowledgments}

The authors are thankful to Chemistry Department, Islamic Azad University of Mashhad and Agricultural Researches \& Services Center, Mashhad, Feyzabad, Iran, Chemistry Department, University of Oslo, Norway for support of this work and with special thanks from Professor. Dr. Mohsen Daneshtalab from School of Pharmacy, Memorial University of Newfoundland, St. John's, Newfoundland, Canada and Professor. Dr. J. (Hans) W.
Scheeren from Organic Chemistry Department, Radboud University Nijmegen, The Netherlands.

\section{LITERATURE CITED}

1. Izumi, Y., Urabe, K. \& Onaka, M. (1992). Zeolite, Clay and Heteropoly Acid in Organic Reactions, Kodansha/VCH, Tokyo.

2. Okuhara, T., Mizuno, N. \& Misono, M. (1996). Advances in Catalysis. Catalytic Chemistry of Heteropoly compounds. 41, $113-252$.

3. Kozhevnikov, I. V. (1998). Catalysis by Heteropoly Acids and Multicomponent Polyoxometalates in Liquid-Phase Reactions. Chem. Rev. 98, 171 - 198. DOI: 10.1021/cr960400y

4. Kozhevnikov, I. V. (2002). Catalysts for fine chemicals, in: Catalysis by Polyoxometalates, vol. 2, Wiley, Chichester.

5. Moffat, J. B. (2001). Metal-Oxygen Clusters. The Surface and Catalytic Properties of Heteropoly Oxometalates, Kluwer Academic Publishers, New York. 
6. Oreste, P., Franca, S. \& Giuseppina, V. (1987). Zinc salt catalyzed rearrangement of acetals of optically active aryl 1chloroethyl ketones: synthesis of optically active 2arylpropionic acids and esters. J. Org. Chem. 52, $10-14$. DOI: $10.1021 /$ jo00377a002.

7. Saunders, M., Chandrasekhar, J. \& Schleyer, P. V. R. (1980). Rearrangements in Ground and Excited States, Academic Press.

8. Barner, B. A. \& Kurland, J. J. (1997). WO 9714669A1.

9. Fan, Q. H., Chen, Y. M., Chen, X. M., Jiang, D. Z., Xi, F. \& Chan, A. S. C. (2000). Highly effective and recyclable dendritic BINAP ligands for asymmetric hydrogenation. Chem. Commun. 789 - 790. DOI: 10.1039/b001503m.

10. Ward, J. Borner, A. \& Kagan, H. B. (1992). Synthesis of 6-endo-hydroxy norphos, a potential ligand for construction of chiral bimetallic catalysts. Tetrahedron: Asymmetry. 3 , 849 - 852. DOI:10.1016/S0957-4166(00)82181-3.

11. Schmidt, R., Foricher, J., Cereghetti, M. \& Schonholzer, P. (1991). Axially Dissymmetric Diphosphines in the Biphenyl Series: Synthesis of (6,6 -Dimethoxybiphenyl2,2 -diyl)bis(diphenylphosphine)( MeO-BIPHEP ) and Analogues via an ortho-Lithiation/Iodination Ullmann-Reaction Approach. Helv. Chem. Acta.74, 370 - 389. DOI: 10.1002/ hlca.19910740215.

12. Bamoharram, F. F., Heravi, M. M., Roshani, M., Jahangir, M. \& Gharib, A. (2007). Effective direct esterification of butanol by eco-friendly Preyssler catalyst, $\left[\mathrm{NaP}_{5} \mathrm{~W}_{30} \mathrm{O}_{110}\right]^{14-}$. J. Mol. Catal. 271, 126 - 130. DOI:10.1016/ j.molcata.2007.02.034.

13. Bamoharram, F. F., Heravi, M. M., Roshani, M., Jahangir, M. \& Gharib, A. (2006). Preyssler catalyst, $\left[\mathrm{NaP}_{5} \mathrm{~W}_{30} \mathrm{O}_{110}\right]^{14-}$ : A green, efficient and reusable catalyst for esterification of salicylic acid with aliphatic and benzylic alcohols. Applied Catalysis A: General. 302, 42 - 47. DOI:10.1016/j.apcata.2005.12.021.

14. Heravi, M. M., Bakhtiari, K., Benmorad, T., Bamoharram, F. F., Heravi, M. M., Oskooie, H. A., \& Tehrani, H. M (2007). Nitration of Aromatic Compounds Catalyzed by Divanadium-Substituted Molybdophosphoric Acid, $\mathrm{H}_{5}\left[\mathrm{PMo}_{10} \mathrm{~V}_{2} \mathrm{O}_{40}\right]$. Monatshefte für Chemie. 138, 5, $449-452$. DOI: 10.1007/s00706-007-0593-6.

15. Hill, C. L. (1989). Catalytic Oxygenation of Unactivated C-H Bonds. Superior Oxo Transfer Catalysts and the Inorganic Porphyrin'. In Activation and Functionalization of Alkanes., Ed., Wiley: New York, pp 243 - 279.

16. Bamoharram, F. F., Heravi, M. M., Roshani, M., Gharib, A. \& Jahangir, M. (2006). A catalytic method for synthesis of $\gamma$-butyrolactone, $\varepsilon$-caprolactone and 2-cumaranone in the presence of Preyssler's anion, $\left[\mathrm{NaP}_{5} \mathrm{~W}_{30} \mathrm{O}_{110}\right]^{14-}$, as a green and reusable catalyst. J. Mol. Catal. 252, 90 - 95. DOI:10.1016/ j.molcata.2006.01.067.

17. Alper, H. \& Hamel, H. (1990). Asymmetric synthesis of acids by the palladium-catalyzed hydrocarboxylation of olefins in the presence of (R)-(-)- or (S)-(+)-1,1'-binaphthyl2,2'-diyl hydrogen phosphate. J. Am. Chem. Soc. 112, 2803 - 2804. DOI: 10.1021/ja00163a053.

18. Romanelli, G., Autino, J. C., Baronetti, G. \& Thomas, H. (2001). H. Efficient Deprotection of Phenol Methoxymethyl Ethers Using a Solid Acid Catalyst with WellsDawson Structure. Molecules. 6, 1006 - 1011. DOI:10.3390/ 61201006. 